\title{
Study of University Online Public Opinion Controlling and Coping Mechanism in Guangdong Province
}

\author{
Zhejun Wang ${ }^{a}$, Ying Jiang ${ }^{b}$, Yuxian Zhong ${ }^{c}$, Lipeng Wan ${ }^{d}$, Leibing Wu ${ }^{e}$, \\ Chulong Luo ${ }^{f}$ and Yufeng Luo ${ }^{g}$
}

School of Management, Beijing Normal University Zhuhai Campus, Zhuhai 519000, China

atianjizhongxuewzj@163.com, bjpz6311whu@bnuz.edu.cn, cjorgezhong@163.com, dwanlipeng@b nuz.edu.cn, ${ }^{\mathrm{P}}$ Wuleibing1121@163.com, fluochulonghl@163.com, 989wind.luo@gmail.com

Keywords: university public opinion, coping mechanism.

\begin{abstract}
From 146 universities in Guangdong province, the author collects university public opinion gathering, university public opinion events and university public opinion department construction by online research and literature research. The author concludes and sums up the characteristics of university online public opinion gathering, classification and characteristics of university online public opinion event and the problems in university public opinion department construction from various angle. According to these information and examples, the author puts forward university online public opinion coping mechanism frame from team building and public opinion department construction. The author also designs coping rules through online public opinion life cycle and combining characteristics of universities.
\end{abstract}

\section{Introduction}

\subsection{Background and Significance of the Research}

Contemporary college students are in the times trend of information. Network media has become a platform where they express their emotions, aspirations, comments and suggestions. However, college students are in the mind semi-mature stage, which are easy to be influenced by harmful environment outside world. So it is of value for college to collect, organize, and analyze the information of online public opinion gathering and to know about college student's psychological state and emotional attitudes. Colleges actively respond to important public opinion, also contributing to propagate positive energy on campus. Simultaneously, the question reflected from public opinion is of reference value for the future development and reform of colleges ${ }^{[6]}$. And colleges set up a good image in the process of control public opinion, redounding to develop the daily management of colleges normally and orderly, conducing to the image and reputation of colleges in society ${ }^{[7]}$.

\subsection{Related Work}

Hebei Normal University Yao Fangfang proposed the reacted Mechanism on colleges for crisis events during the current media environment. She considered that it should be established four mechanisms, they are leading mechanism of public opinion, rank safeguard mechanism of public opinion, the interaction mechanism of public opinion and work feedback mechanisms of public opinion $^{[1]}$. Central China Normal University Yi Tianyuan, according to the features of the current information age, put forward construction of the college online public sentiment warning mechanisms principle ${ }^{[2]}$. Anhui Agricultural University Song Shuai believed that the reactions of colleges emergency events should include emergency response before, during, and afterwards, emphasizing the importance of the platform building and team overseeing ${ }^{[3]}$; Shanxi University of Finance Yao Jian presented that many problems existed in college online public opinion environment ${ }^{[4]}$; Hu Qiming, Wang Jian and Chen Zhangting established the multidimensional model about university online public opinion and put forwad coping measures ${ }^{[5]}$. 


\section{The Public Opinion Survey and Analysis of Universities in Guangdong Province}

We did an investigation that which departments in monitoring and guiding public opinion play role. As shown in Table 1:

Table 1 Department of Guangdong college public opinion subtotals table

\begin{tabular}{ccccccc}
\hline $\begin{array}{c}\text { Department } \\
\text { of public } \\
\text { opinion }\end{array}$ & Office & $\begin{array}{c}\text { Student } \\
\text { organizations }\end{array}$ & $\begin{array}{c}\text { News } \\
\text { sector }\end{array}$ & $\begin{array}{c}\text { Logistics } \\
\text { sector }\end{array}$ & $\begin{array}{c}\text { Publicity } \\
\text { department }\end{array}$ & $\begin{array}{c}\text { Public } \\
\text { opinion } \\
\text { department }\end{array}$ \\
\hline Quantity & 27 & 25 & 13 & 12 & 12 & 1 \\
\hline
\end{tabular}

As the table shows, most of them apply for multiple ways in some relevant colleges of public opinion. Only one college established the specific public opinion department--Guangdong Baiyun University, but limited by the inefficient ways of artificial reported and restriction of labor and funding. The relevant college public opinion departments are not professional and specialized, by means of multiple ways, which will decrease the sensitivity of opinion public opinion for college so that availability and practicality of online public opinion will be reduced greatly.

We classified and counted for department construction of Guangdong university public opinion from the two aspects running properties and running size respectively. As shown in Table 2.

Table 2 The properties of Guangdong university public opinion

\begin{tabular}{cccccc}
\hline $\begin{array}{c}\text { Running } \\
\text { properties }\end{array}$ & $\begin{array}{c}\text { Public regular } \\
\text { college }\end{array}$ & $\begin{array}{c}\text { Private regular } \\
\text { college }\end{array}$ & $\begin{array}{c}\text { Public special } \\
\text { college }\end{array}$ & $\begin{array}{c}\text { Private } \\
\text { special college }\end{array}$ & $\begin{array}{c}\text { Independent } \\
\text { college }\end{array}$ \\
\hline $\begin{array}{c}\text { Accounting } \\
\text { for }\end{array}$ & $72.97 \%$ & $71.43 \%$ & $67.27 \%$ & $60 \%$ & $58.82 \%$ \\
\hline
\end{tabular}

We can draw a conclusion that regular college's department construction of public opinion is better than special college's and independent college's. Colleges that noticed the importance of online public opinion are shortage in the construction of public opinion department and invest less. Both of the two questions directly affect college on the monitoring and guiding of online public opinion.

\section{Analysis of University Online Public Opinion in Guangdong Province}

Via research, the author finds that gathering places of university online public opinion in Guangdong province are mainly in post bar, BBS, micro-blog and the network media platform of universities. Although these media are affiliated with the gathering place of the online public opinion of universities, each of them still has characters and advantages ${ }^{[10]}$. The author will have a specific discussion on these four kinds of public opinion gathering place.

Micro-blog mainly draws attention from spreading the recent events while the post bar, BBS and the colleges and universities' own network media will pay attention on the comprehensive detail of these events ${ }^{[8]}$. To show more detail of the events to us can make us understand or discuss the events in depth. Post bar, BBS, micro-blog and the universities' own network media, the generation and head of university public opinion, are the main parts of university online public opinion gathering. There are many different characteristics in those four kinds of gathering but such characteristics among them fill with each other and make them become a complete system ${ }^{[9]}$.

According to the different emphasis, the author divides the online public opinion events into four categories: negative public opinion events, public crisis, emergencies and group incidents

\section{University Online Public Opinion Response}

Summing up the above, the author put forward a coping mechanisms, the overall framework is shown in figure1. 


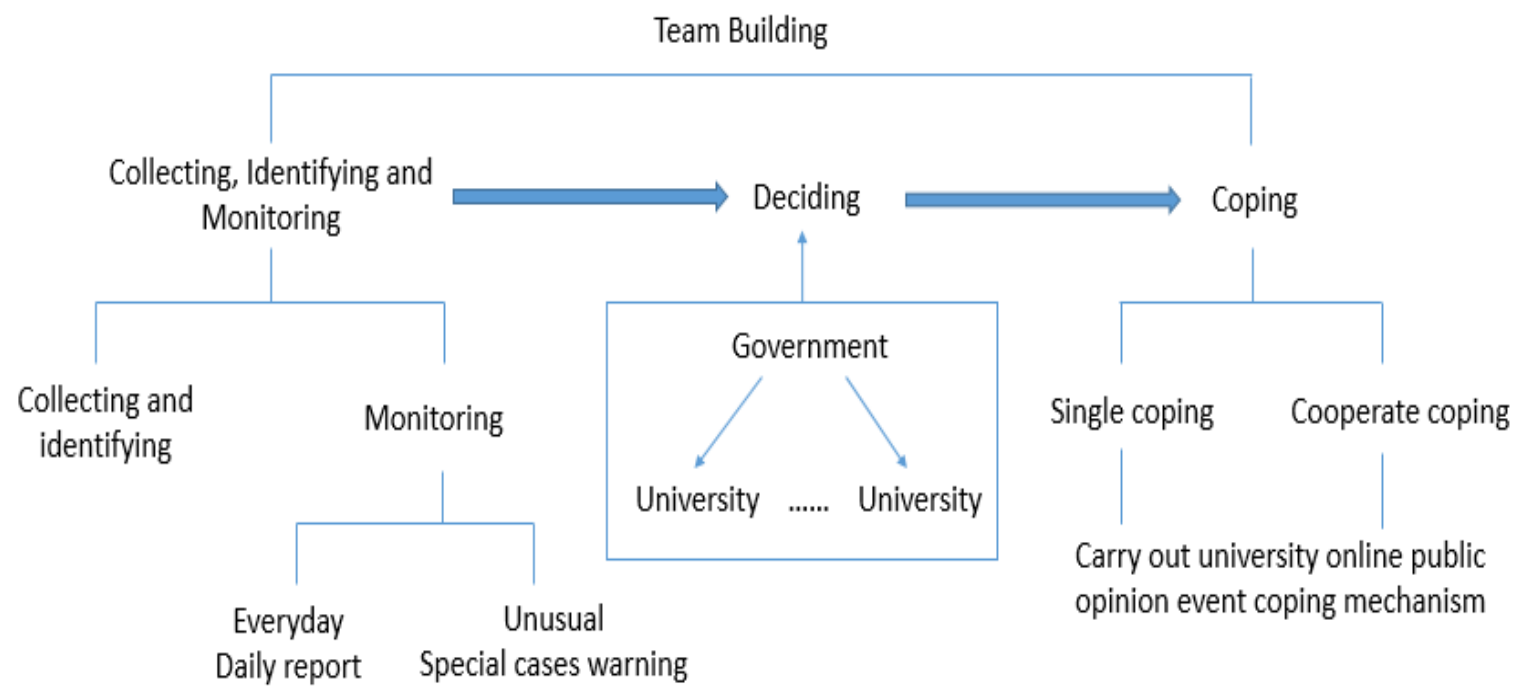

Fig. 1 Coping mechanism overall framework

The analysis shows that the online public opinion involves a wide scope, and has complex group. Therefore, when public opinion occur, the scope of its impact could cover the whole of various colleges and universities in Guangdong province, and then spread to the society by the colleges and universities, and ultimately being difficult to control. Therefore, we need to build a distributed teams, team makes government as the center and spreads to various colleges and universities, to control the public opinion of large impact scope.

\subsection{Dual monitoring}

Due that there are many kinds of online public opinion events in universities and different factors which give rise to them, the public opinion events have the complexity and unpredictability. Whether the type of public opinion event, or the place it happens, or its range of influence, are hard to predict. In view of the two features of public opinion event, the design of scheme include a dual monitoring mechanism of network public opinion department locate is the place where the online public opinion events happen and where the public opinion produce. So the monitoring team is configured by the university online public opinion department is the first monitoring point. Second, the monitoring team of the government online public opinion department is the second monitoring point. This monitoring point can act as the alley of the first point. This monitoring point can act as the alley of the first point. At the same time, owing that this point is set in the government, the monitoring scope can spread all the universities of Guangdong province to solve the situation when public opinion have spread to other universities or society.

\subsection{Constructing Information Network}

Due that the scope of the university online public opinion events are hard to predict and they develop rapidly, we need to build an information network to collect, summarize, analyze the public opinion information of all the universities, to cope with larger efficient network public opinion information events, at the same time to prevent such events happening in other universities. In this scheme, the information sharing network is composed of the monitoring team. The monitoring team of university public opinion department can share information with the monitoring team of government. At the same time, the monitoring team of government can share the other universities' public opinion information in Guangdong province with the appointed universities.

\subsection{Making Coping Measures}

Because of the complexity and diversity of the university online public opinion events, the fixed scheme often can't achieve the predicted effect. So it is necessary to make coping measures separately to effectively cope with public opinion event. In this scheme, the decision-making team will follow this principle, with the effective information provided by the monitoring team, to make a fully analysis to the event and then quickly make a set of effective coping strategy. 


\subsection{Executing Quickly}

Due that the occurrence and development of university online public opinion is very fast and it also has emergency situation, the quick reaction is needed. This scheme includes an executive team and the function of it is to quickly implement measures to handle public opinion events rapidly and remove the public mood.

\section{Summary}

The tide of information age enters into universities, it's an important thing to universities to monitor and coping university online public opinion. It not only is good for the universities' harmony and stability, but also it is good for the image and reputation of university. For university, the first is to cognizing the great value of online public opinion, and meanwhile, putting into people, money and resource to monitor and lead online public opinion to positive coping. What's more, university should strengthen the combination with other universities and government, discussing the coping ways of great public opinion event and deal with cooperate coping to reach regional and systemic university online public opinion coping. Concretely, in daily management work, university should pay attention to collect public opinion information and sum up a valid response. When public opinion event happens, university should analyze the characteristics of public opinion event rapidly and truly, and should adopt related measures according to scope of influence and degree of influence. Either on university own, or cooperate coping.

\section{Acknowledgement}

This work is supported by a project of Guandong Province Moral Education Innovation (Project No. 2015DYZD015). It's also supported by a grant from Science and Technology Plan Project of Guangdong Province (Project No. 2014A080804001).

\section{References}

[1]. Yao Fangfang. Research on the esponse mechanism of college public opinion crisis in self-media environment (Master degree, Hebei Normal University, China, 2013). p.108-161

[2]. Yi Tianyuan. Research of college online public opinion early warning mechanism (Master degree, Central China Normal University, China, 2013). p. 57-98.

[3]. Song Shuai. The study of response mechanisms for internet public opinion on university emergencies (Master degree, Anhui Agricultural University,China, 2012). p.67-125.

[4]. Yao Jian, The research of problem about current Chinese universities Public Opinion on Internet (Master degree, Shanxi University of Finance and Economics, China, 2013). p. 189-240.

[5]. Hu Qiming, Wang Jian. Public Opinion Research of University Network Interactive Platform under the Complexity Theory. 2011 International Conference on Intelligent Computing and Integrated System (ICISS 2011). Guilin Guangxi Province China, 2011-10-24. p.4.

[6]. Bian Jun. Study on the management for the internetsentiments information in university (Master degree, Henan University, China, 2011). p.1-74.

[7]. Fan Chenxi, Han Songyang. Repositioning on Coping Strategies of College Network Public Opinion in Big Data Era. Journal of Shanxi Academy of Governance. Vol. 29(2015)No. 1.p. 33-36.

[8]. Zhou Tao. Ideological and political education system in universities under the environment of public opinions on internet (Doctor degree, Southwestern University of Finance and Economic, China, 2011).p.1-55 
[9]. Zhang Jihong. The Research on the Legal Countermeasures of the College Students' Mass incidents (Doctor degree, Jilin University, China 2014). p.150-187.

[10]. Wang Lei. Study on Ideological and Political Education of University Students in Unexpected Events (Master degree, Hebei University of Economics and Business, China 2014). p.90-144. 